\title{
Descrição Iconográfica de Cartilhas de Acessibilidade Urbana: análise de representações gráficas do espaço público de calçadas
}

\author{
Iconographic Description of Urban Accessibility Booklets: analysis \\ of graphic representation of the sidewalks public space
}

\author{
MAÍRA LAURENÇA GEIA \\ Arquiteta e Urbanista, Mestranda em Arquitetura, Tecnologia e Cidade - UNICAMP, \\ ma.geia@hotmail.com \\ NÚBIA BERNARDI
}

Arquiteta e Urbanista, Docente na Faculdade de Engenharia Civil, Arquitetura e Urbanismo, UNICAMP, nubiab@unicamp.br

\section{RESUMO}

A história do homem é marcada por grandes descobertas, dentre elas, os mecanismos de comunicação e dentre estes, a imagem. A maneira de analisar uma imagem é concebida de formas distintas por vários autores, dentre eles, Panofsky (1991) com a análise iconográfica. Além da iconografia como prática, também existe o aspecto que busca entender como a iconografia faz parte de estudos relacionados à arquitetura. A pesquisa aqui descrita apresenta uma análise de cartilhas de acessibilidade, ergonomia e inclusão e busca entender o parâmetro iconográfico presente nas representações gráficas de cartilhas de acessibilidade distribuídas no Brasil. O objetivo deste artigo é apresentar uma avaliação sobre a inclusão de parâmetros de Desenho Universal, presentes em cartilhas sobre acessibilidade, ergonomia e inclusão questionando seus impactos. Esta pesquisa está baseada em duas etapas metodológicas: revisão da literatura e análise iconográfica de cartilhas do CREA (Conselho Federal de Engenharia e Agricultura), com enfoque em acessibilidade urbana. Esperase verificar como os materiais iconográficos disponibilizados através de diferentes fontes podem contribuir para um olhar crítico sobre a aplicação dos conceitos de Desenho Universal em projetos de arquitetura e urbanismo.

PALAVRAS-CHAVE: Acessibilidade; Iconografia; Desenho Universal.

\section{ABSTRACT}

The history of man is marked by great discoveries, among them, the mechanisms of communication and among these, the image. The way of analysing an image is conceived in different ways by several authors, among them, Panofsky (1991) with iconographic analysis. In addition to iconography as a practice, there is also the aspect that seeks to understand how iconography is part of studies related to architecture. The research described here presents an analysis of booklets on accessibility, ergonomics 


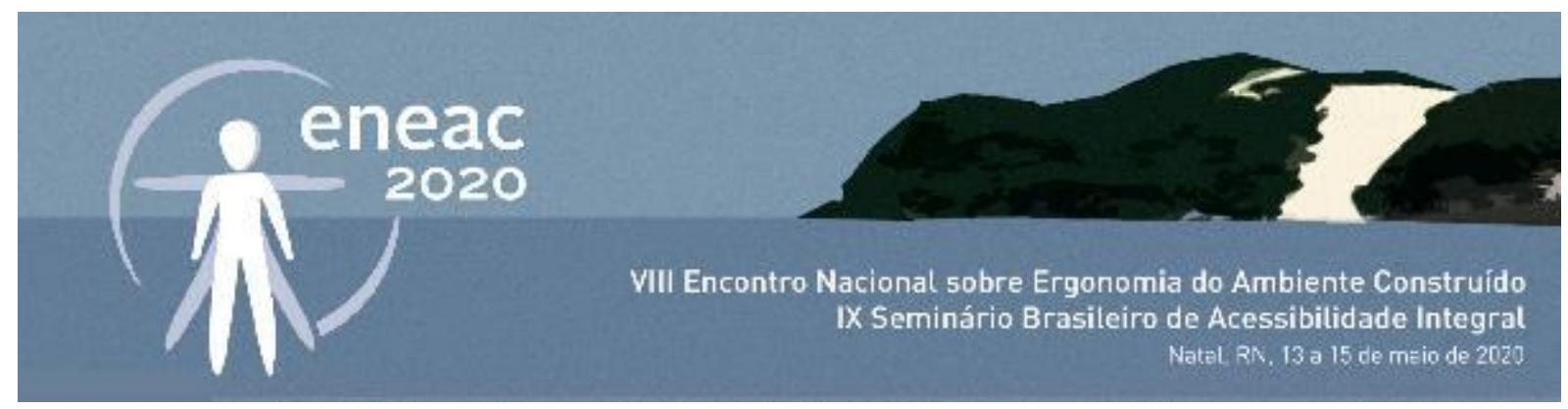

and inclusion and seeks to understand the iconographic parameter present in the graphic representations of booklets distributed in Brazil. The objective of this article is to present an evaluation on the inclusion of Universal Design parameters, present in booklets on accessibility, ergonomics and inclusion, questioning their impacts. This research is bases on two methodological steps: literature review and iconographic analysis of booklets by CREA (Federal Council of Engineering and Agriculture, with a focus on urban accessibility. It is expected to very how the iconographic materials made available through different sources can contribute to a critical look at the application of Universal Design concepts in architecture and urbanism projects.

KEYWORDS: Accessibility; Iconography; Universal Design.

\section{INTRODUÇÃO}

A questão da deficiência física passou a ter maior visibilidade a partir da segunda metade do século XX. Em 1948 a Organização das Nações Unidas, ONU, apresentou a Declaração Universal dos Direitos Humanos, constando que: "Todos os seres humanos nascem livres e iguais em direitos" (ONU, 1948). No Brasil, a Constituição de 1988 prevê em seu artigo quinto, que todos são iguais perante a lei, não importando sexo, deficiência e restrição, todos têm direito à vida, à segurança e à propriedade. Em 2006, houve a Convenção das Nações sobre Direitos das Pessoas com Deficiência, que surgiu como um instrumento para os direitos humanos e foi adotada em 2008, trazendo categorizações dos tipos de deficiência, direitos e liberdades.

Em 2013, o IBGE apresentou dados da Pesquisa Nacional de Saúde (PNS) sobre deficiências no Brasil, levando em conta deficiências temporárias, permanentes, progressivas, regressivas, estáveis, intermitentes e ou contínuas de deficientes intelectuais, físicos, auditivos e visuais. Segundo a pesquisa, 6,2\% da população no Brasil maior de dezoito anos tinha ao menos uma deficiência. Dados da OMS (ONU) de 2011 indicam que um bilhão de pessoas vivem com alguma deficiência, e que, 80\% delas, vivem em países em desenvolvimento.

$\mathrm{Na}$ arquitetura especificamente, existem medidas de identificação de obstáculos, barreiras físicas e ambientais, que podem ser observadas, por exemplo: no estado de conservação, no atendimento de normas (NBR's), em obstáculos que limitem ou impeçam o acesso e a liberdade de movimento, a privação ou dificuldade de circulação com segurança, a facilidade de comunicação e de informação, a existência de produtos, instrumentos e tecnologia adaptados a atender a funcionalidade da pessoa com deficiência. Deste modo, a arquitetura, que aplica a técnica de organizar e criar espaços para abrigar diversas atividades, tem um papel fundamental e essencial para gerar inclusão, mobilidade, segurança e autonomia das pessoas, nos ambientes. Considerando o exposto na visão arquitetônica, ressaltamos o Desenho Universal como concepção de produtos, ambientes e serviços, a serem usados de forma a propiciar maior adequação aos usuários, sem necessidade de adaptar o ambiente.

$\mathrm{O}$ arquiteto norte-americano Ron Mace, ressaltou que, considerar a partir do início de um projeto, a diversidade das necessidades humanas é a definição original e fundamental do conceito de Desenho Universal (MACE, 1996), isto é, projetar para a necessidade. Atualmente o Desenho Universal tem atuações em diferentes áreas como no urbanismo, na construção, no design de objetos, na comunicação e em todas as áreas que necessitam de um projeto adequado a todas as pessoas. Aos poucos, e ao longo de décadas, as pessoas com deficiência foram conquistando direitos, mas discutir 


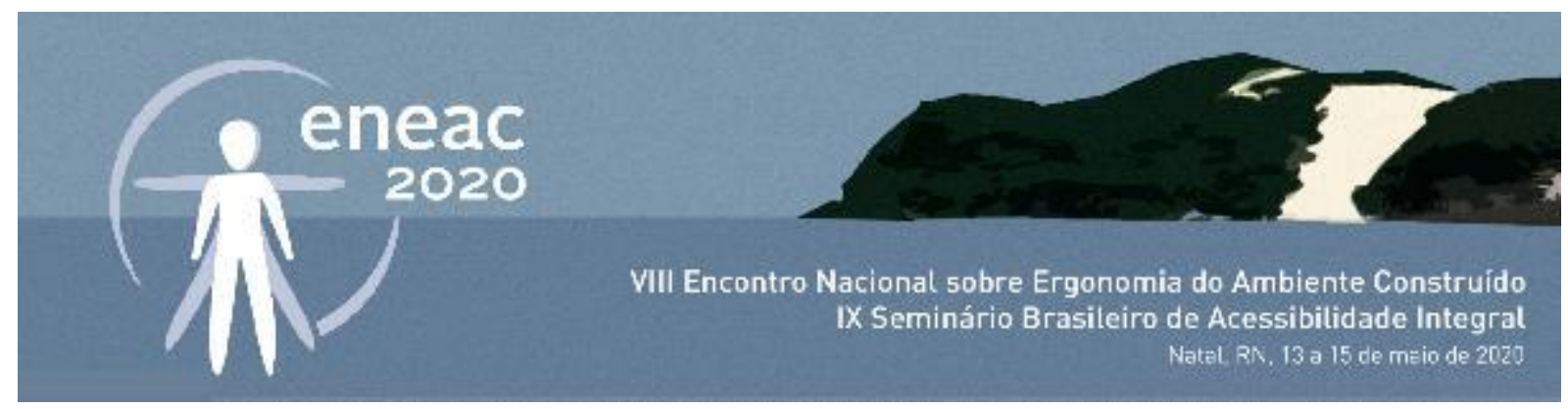

esse tema continua de suma importância para garantir a aplicação e validação desses direitos adquiridos.

\begin{abstract}
O processo de inclusão vem sendo aplicado em cada sistema social. Assim existe a inclusão na educação, no lazer, no transporte etc. Quando isso acontece, podemos falar em educação inclusiva, no lazer inclusivo, no transporte inclusivo e assim por diante. Uma outra forma de referência consiste em dizermos, por exemplo, educação para todos, lazer para todos, transporte para todos. (Sassaki, 1997, p.41)
\end{abstract}

Desde a revisão da Norma NBR9050 no ano de 2004, muitos materiais complementares sobre acessibilidade foram impressos e distribuídos em formato de cartilhas de orientação, com o intuito de difundir os conceitos da acessibilidade arquitetônica aplicáveis ao ambiente construído e urbano. Tendo em vista a importância destes materiais complementares à Norma, como substrato formador e de conscientização sobre as questões das deficiências e da necessidade de acesso livre de barreiras arquitetônicas, torna-se necessário compreender se materiais disponíveis e entregues aos profissionais de engenharia, de arquitetura, e à população, relacionados à estruturação de projetos de acessibilidade ou de seu uso, alcançam o que se pretende e levam à real aplicação das observações nelas contidas. Não é objetivo desta pesquisa realizar uma análise iconográfica da Norma NBR9050, mas sim das cartilhas que fazem menção aos aspectos de acessibilidade descritos na normatização e legislação brasileiras.

Considerando a importância da linguagem Iconográfica como mecanismo de potencialização da compreensão de informações, necessita-se compreender se tais cartilhas utilizam esta linguagem de modo eficiente para a transmissão das informações relacionadas aos conceitos e à legislação de acessibilidade no ambiente construído, possibilitando um auxílio adequado aos projetistas e profissionais envolvidos, tanto na compreensão quanto na garantia de qualidade dos projetos arquitetônicos. A pesquisa se justifica pela quantidade de materiais de auxílio que foram elaboradas e distribuídas ao longo dos últimos anos e pela necessidade de verificar o conteúdo e a forma de inserir informações que se quer transmitir ao leitor.

\title{
1.1Conceitos de Iconografia
}

A história do homem é marcada por grandes descobertas, dentre elas, os mecanismos de comunicação e dentre estes, a imagem. A maneira de analisar uma imagem é concebida de formas distintas por vários autores. Panofsky (1991) foi um dos principais estudiosos de iconografia, tendo vivido entre 1892 e 1968. Seus estudos foram fundamentados em análises de obras de arte e proposta metodológica com um pilar em iconografia e iconologia, isto é, o primeiro, o estudo de um tema e o segundo estudo do significado do objeto. $O$ grupo mais famoso de iconografistas de que se tem registro são os estudiosos da Escola de Warburg, Aby Warnurg (1866-1929), arqueólogo e paleontólogo alemão do século XIX, construiu uma nova vertente da teoria e história da arte. Ele desenvolveu uma nova disciplina que extrapolou os domínios da história da arte, a disciplina Iconologia. Contudo, mesmo que Warburg tenha iniciado a corrente de estudos sobre o assunto, foi Panofsky quem conquistou maior expressão nos estudos na área, conseguindo sintetizar ideias e abordagens discutidas na Escola em um famoso artigo intitulado "Iconografia e Iconologia: uma introdução ao estudo da arte da renascença". Panofsky publicou também um livro "Estudos da Iconologia" que teve grande importância à Biblioteca de Warburg. 


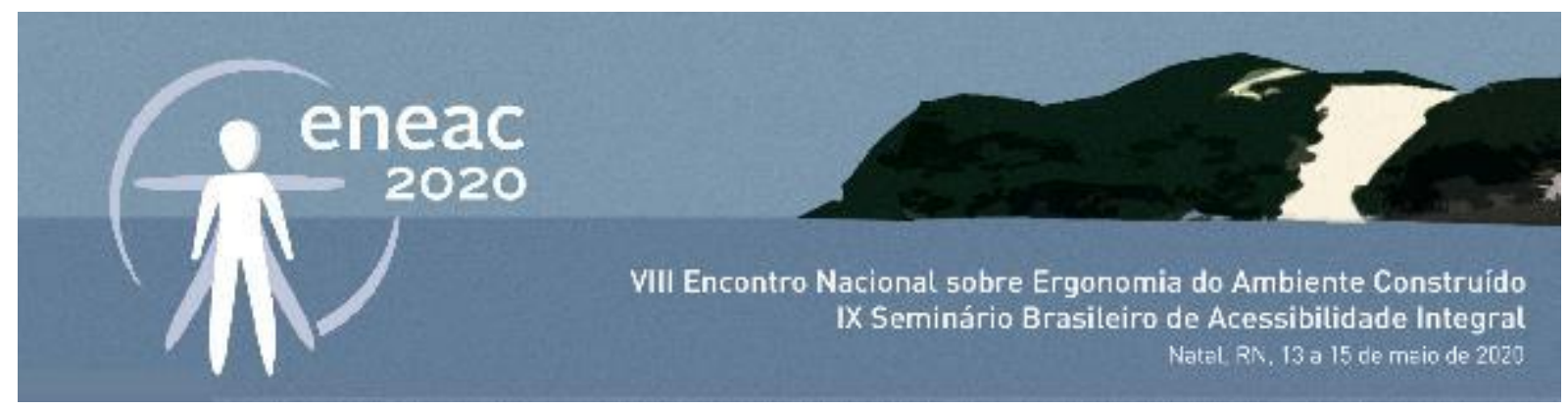

iconografia seria o "ramo da história da arte que se preocupa com o conteúdo ou sentido das obras de arte em oposição a sua forma" (PANOFSKY, 1991, p.47). A interpretação iconológica permite observar e considerar o significado da obra segundo seu exterior construtivo, segundo Panofsky existem três estratégias de compreensão de uma obra de arte: primeiro a história dos estilos, que busca compreender como, sob diferentes condições históricas objetos e fatos foram expressos pelas formas; segundo, a história dos tipos, que busca compreender como, sob diferentes condições históricas, temas específicos e conceitos foram expressos por objetos e fatos; e terceiro, a história de sintomas culturais, que busca compreender como, sob diferentes condições históricas as tendências gerais e essenciais da mente humana foram expressas por temas específicos e conceitos.

A análise iconográfica é classificada por três níveis de interpretação, segundo Panofsky. O primeiro, chamado de descrição pré-iconográfico está relacionado ao significado primário, que consiste em identificar formas, objetos e eventos presentes na imagem, requer o reconhecimento de um conjunto de formas com os motivos artísticos. Limita-se aos motivos como linhas, cores e volumes. "Consistindo na identificação de objetos (tais como árvores, prédios, animais e pessoas) e eventos (refeições, batalhas, procissões etc.)" (BURKE, 2004, p.58).

O segundo, chamado de descrição iconográfica, está relacionado ao significado secundário, que se difere pois consiste na ligação das composições da imagem com assuntos e conceitos da percepção das convenções sociais e culturais. Panofsky descreve como: "[...] método de proceder puramente descritivo, ou até mesmo estatístico. A iconografia é, portanto, a descrição e classificação das imagens [...]".

Já o terceiro nível, chama-se descrição iconológica, está relacionado ao significado intrínseco, em que a descrição é definida por conseguir descobrir a interpretação dos valores simbólicos da imagem, onde estão entrelaçadas preocupações do contexto na produção, como fatores históricos e sociais. Todo esse processo necessita de um alcance de visão ao material disponível, aos registros disponíveis, a decodificação quanto à teoria cultural, social e econômica. E por fim, uma análise e interpretação das informações colhidas.

Sabe-se, contudo, que são conhecidas lacunas da proposta de Panofsky. Ao pontuá-la como fundamentação para o tratamento das imagens, sabe-se dos riscos que todos aqueles que se propõem a trabalhar com fontes imagéticas correm, pois, a variedade de possibilidade e abrangências que essas fontes oferecem é indescritível. O historiador inglês Peter Burke (2004, p.44) explica que os historiadores de arte que se opunham à superficialidade na interpretação das imagens feitas pela análise formal eram chamados iconografistas, esses diziam que "as pinturas não são concebidas simplesmente para serem observadas, seriam também para serem lidas". O livro "Testemunho Ocular" de Burke (BURKE, 2004) que se dedica ao "uso da imagem como documento histórico" apresenta um capítulo sobre iconologia e uma epígrafe de Panofsky.

Além da iconografia como prática, também existe o aspecto que busca entender como a iconografia faz parte de estudos relacionados à arquitetura e os primeiros passos em relação à representação através de desenhos e plantas arquitetônicas. Essa relação teve um grande início com estudos e produção de conhecimento arquitetônico. "Arquitetos tratadistas utilizavam recursos modernos de representação que influenciaram direta ou indiretamente muitos projetos e permitiram muitos avanços interpretativos para a história da arquitetura". (TOGNON 2011). A descoberta dos manuscritos de Vitruvius causou grande impacto por muitos séculos em todo o mundo ocidental. Até este momento histórico, a única forma de se lembrar de lugares ou construções era meramente pela 


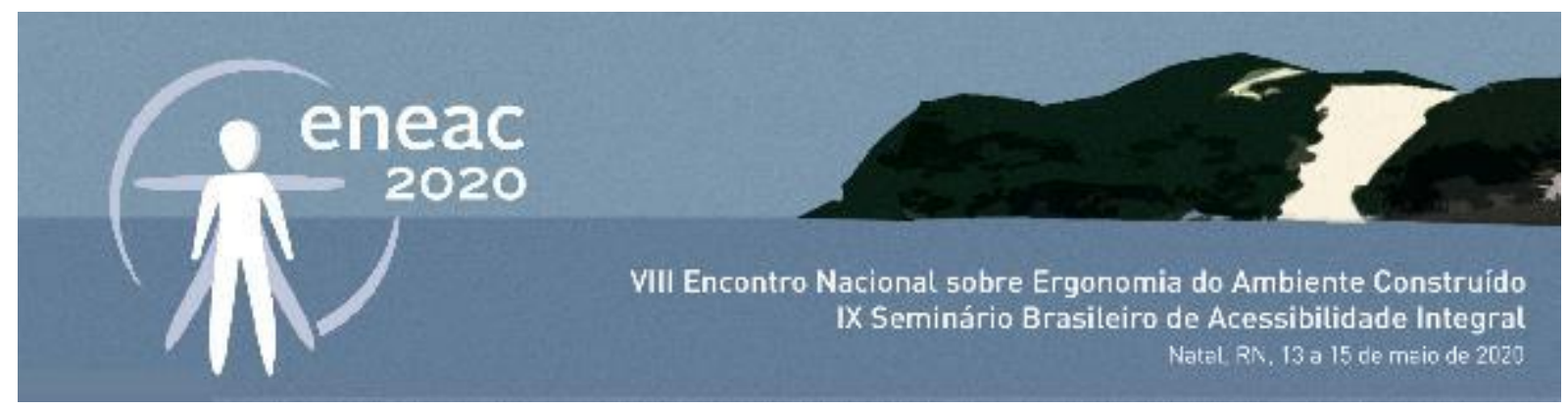

memória ou se fosse o caso através de croquis e desenhos como um meio de materializar um ideal sociocultural.

Todos os estudos dos tratados são ideias traduzidas em desenhos que tiveram grande impacto no âmbito arquitetônico, mostrando que a arquitetura e iconografia podem servir como diálogo entre sociedade, tempo, espaço e cultura além do retrato histórico. Segundo Peter Burke (BURKE 2004) em um contexto social e cultural a memória então se tornaria memória social e poderia justificar ações no presente com referência ao passado. Existiam muitas relações de poder a partir da arquitetura e iconografia antiga e existem muitos estudos relacionados a isso, estudos de prédios públicos, moradias privadas, monumentos funerários, catedrais, palácios e a própria representação das cidades é algo bem forte. A iconografia como instrumento de análise foi muito utilizada na elaboração de signos gráficos, e por meio dela, faz-se uma releitura estilizada na elaboração de grafismo da arquitetura, da fauna, da flora, e dos elementos culturais do lugar a ser pesquisado.

A pesquisa aqui descrita apresenta uma análise de cartilhas de acessibilidade, ergonomia, inclusão e Design Universal, buscando entender sob o parâmetro iconográfico as representações gráficas de cartilhas de acessibilidade distribuídas no Brasil. Entende-se que os materiais iconográficos disponibilizados através de diferentes fontes, podem contribuir para um olhar crítico sobre a aplicação dos conceitos de Desenho Universal e ainda para compreensão de normas e legislações sobre acessibilidade em projetos de arquitetura e urbanismo. A análise iconográfica pretende construir interpretações mais amplas e de melhor qualidade em diversos aspectos relacionados a acessibilidade. Ainda há de se destacar que a melhor adequação dos aspectos iconográficos, facilita a compreensão e estudo de vários aspectos relacionados as questões que se propõem, nesse caso, de acessibilidade, ergonomia, inclusão e Desenho Universal. Embora a pesquisa tenha realizado uma análise iconográfica completa das cartilhas, ou seja, foram realizadas as 3 etapas descritas por Panofsky - descrição pré-iconográfica, descrição iconográfica e descrição iconológica - este artigo irá apresentar apenas a etapa de descrição iconográfica de 3 cartilhas pré-selecionadas, considerando também os conceitos de Desenho Universal.

\section{METODOLOGIA}

Este artigo apresenta uma investigação sobre como materiais iconográficos podem auxiliar na leitura e interpretação de imagens presentes em cartilhas de orientação sobre acessibilidade e Desenho Universal. Observando a disponibilidade e oferta desses materiais em diferentes estados do Brasil, esta pesquisa se apoia em duas etapas metodológicas: revisão da literatura e análise iconográfica. Na referida pesquisa, foram selecionados um grupo de 55 cartilhas, sendo 22 delas do CAU e CREA. Para o escopo deste artigo, foram utilizadas 3 cartilhas publicadas com apoio do CREA (Conselho Federal de Engenharia e Agricultura) que tem em comum a temática de orientações de acessibilidade em calçadas. Embora as cartilhas apresentem orientações sobre o ambiente construído em geral, a escolha da temática sobre acessibilidade em calçadas foi adotada como parâmetro de comparação de informações e conteúdo, para apresentação neste artigo. A Figura 1 apresenta o fluxograma da pesquisa.

1a etapa: Revisão da literatura: do tipo bibliográfica, usando como fonte artigos e teses de pesquisadores que são referência na área de acessibilidade, Universal Design, acessibilidade arquitetônica, legislação e normas vigentes. Também foram estudados os preceitos de uma análise 


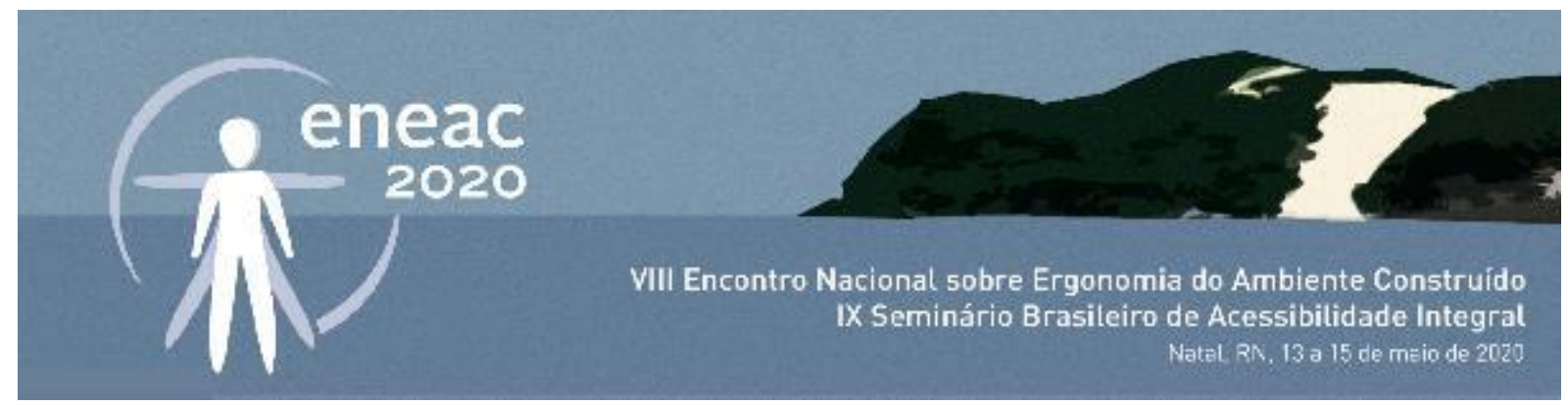

iconográfica e iconografia aplicada à arquitetura, com a finalidade de estabelecer critérios para a análise das cartilhas.

2a etapa: Análise Iconográfica: a análise iconográfica é um método puramente descritivo de coleta e classificação. É classificada por três níveis de interpretação, segundo Panofsky (PANOFSKY, 1972 apud MOLINA) sendo eles: descrição pré-iconográfica, descrição iconográfica e descrição iconológica. Inicialmente foi realizada também a Indexação e Estrutura Estilística das cartilhas.

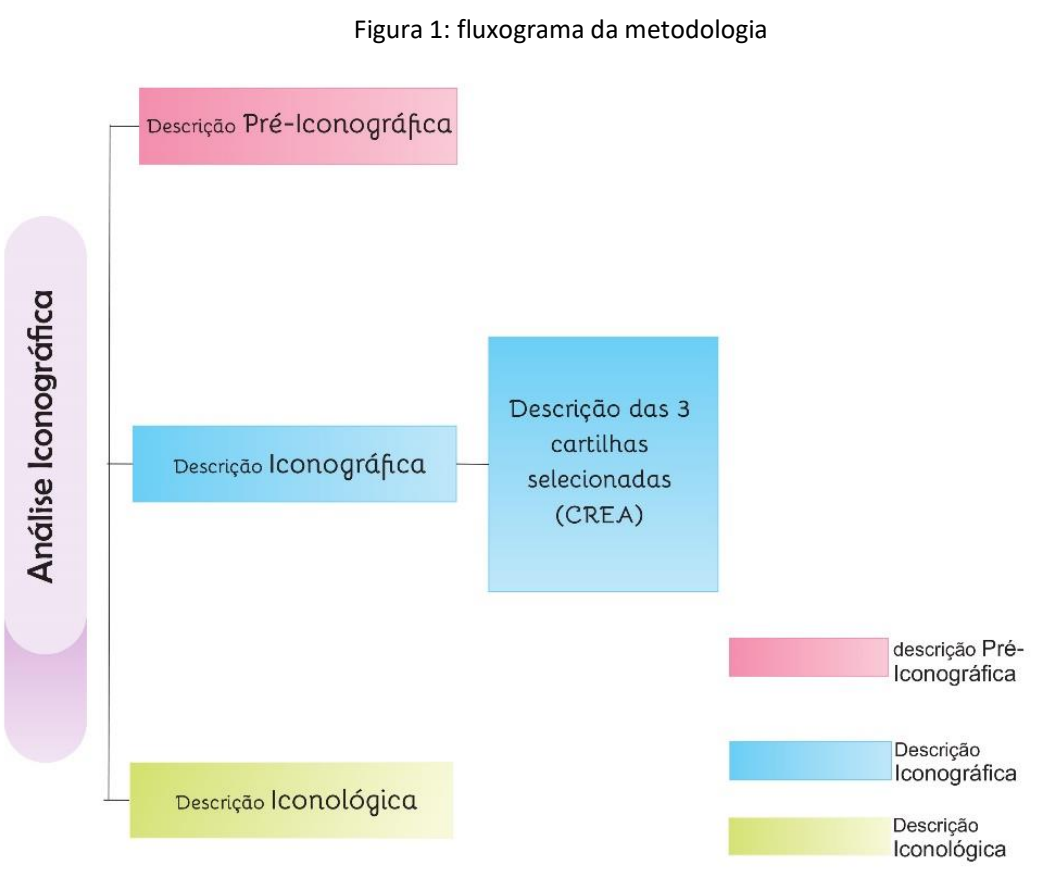

Fonte: elaborado pelos autores.

1. Descrição pré-iconográfica: não será apresentada neste artigo;

2. Descrição iconográfica: é composta do significado secundário ou convencional, que se difere, pois consiste na ligação das composições da imagem com assuntos e conceitos da percepção das convenções sociais e culturais. Será apresentada neste artigo;

3. Descrição iconológica: não será apresentada neste artigo.

\section{DESENVOLVIMENTO DA PESQUISA - DESCRIÇÃO ICONOGRÁFICA}

Segundo Panofsky (1991), a descrição Iconográfica está relacionada ao nível secundário, onde se define o significado da imagem a partir de elementos identificados no nível pré-iconográfico. Nessa etapa é que se ligam os motivos artísticos e as combinações de motivos artísticos. Panofsky destaca que, como se trata de imagens de estórias e alegorias, a análise iconográfica mais do que requer experiências práticas, requer uma familiaridade com conceitos e temas específicos que podem ser adquiridos por meio de fontes literárias (PANOFSKY, 1991). A descrição foi feita utilizando como base as informações da tabulação das cartilhas analisadas. 


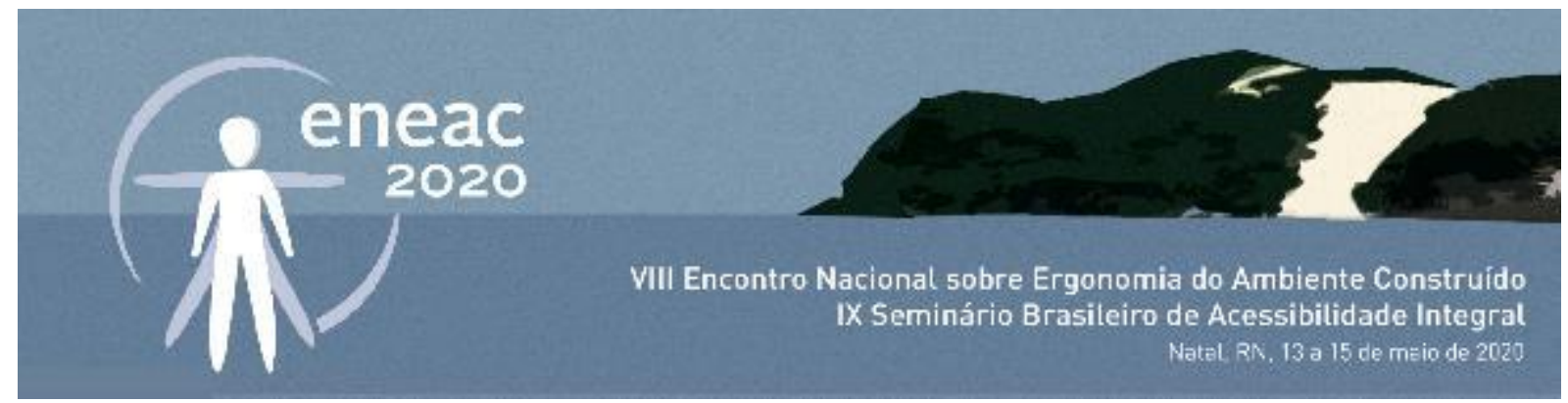

A seguir são apresentadas as 3 (três) cartilhas selecionadas, do universo de 55 (cinquenta e cinco) analisadas na pesquisa completa. As cartilhas forma numeradas conforme a sequência de análise das 55 cartilhas que compõem a pesquisa maior:

1. Cartilha no. 34. CREA-BA. Guia Prático para a Construção de Calçadas. 2a ed. Salvador. 20072010;

2. Cartilha no. 39. PREFEITURA DE MACEIÓ. Cartilha de acessibilidade das calçadas de Maceió superintendência municipal de controle do convívio urbano -AL. Maceió;

3. Cartilha no. 40. PREFEITURA DE MANAUS. Calçada Legal. Como vai sua calçada? Manaus. 2017;

\section{DESCRIÇÃO ICONOGRÁFICA DAS CARTILHAS}

A Cartilha no 34, "Guia Prático para a Construção de Calçadas" teve a 2a edição entre 2007 e 2010, publicado na cidade de Salvador- BA (Figuras 2 e 3).

Figura 2: Cartilha no. 34.

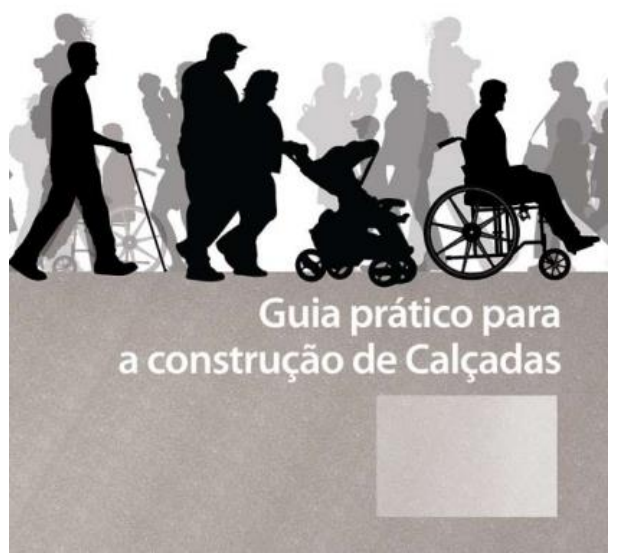

Fonte: http://solucoesparacidades.com.br/wp-content/uploads/2012/08/Guia_construcao_calcadas.pdf

Na capa (Figura 2) pode-se observar imagens e em linguagem escrita um título. As figuras humanas são representadas em grupos, sem qualidades expressionais visíveis. As representações são de deficiente visual, um homem com bengala; dificuldade de locomoção, representada por um homem com sobrepeso, e uma mulher levando um carrinho de bebê, provavelmente lactante; deficiente físico, representado por um homem na cadeira de rodas; e o que podemos observar é que ao fundo existem várias outras representações que em geral são mulheres. A cartilha expressa acessibilidade atitudinal, no sentido do convívio conjunto entre pessoas com diferentes habilidades. As imagens contém linhas retas e curvas e predomínio de cores em preto e branco. $\mathrm{O}$ ambiente não é 


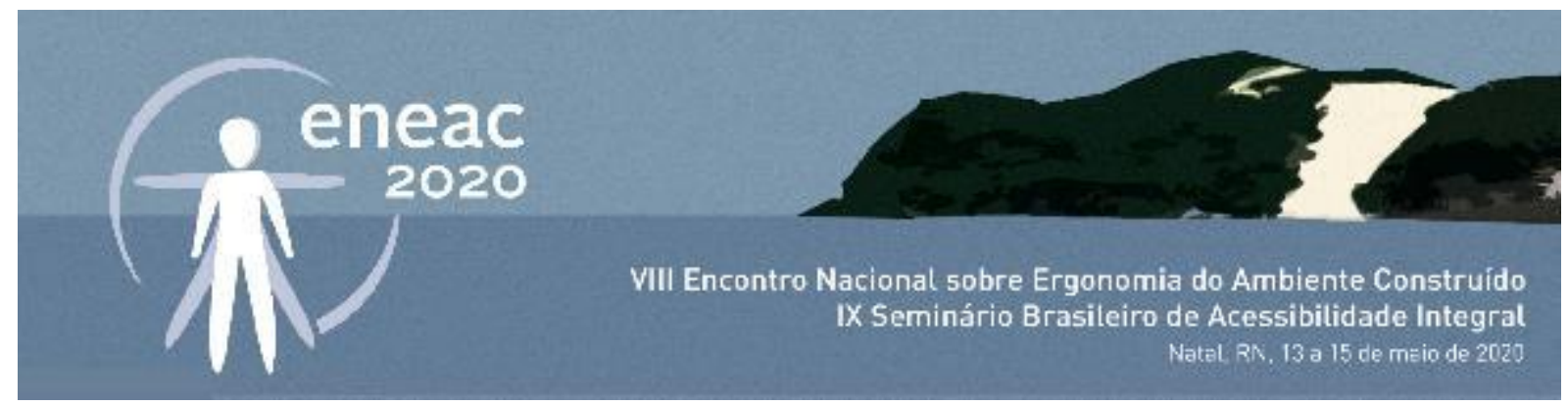

propriamente definido, e os volumes representados são basicamente equipamentos como bengala, carrinho de bebê e cadeira de rodas, fazendo referência à áreas de circulação.

Figura 3: Cartilha no. 34, desenho na calçada.
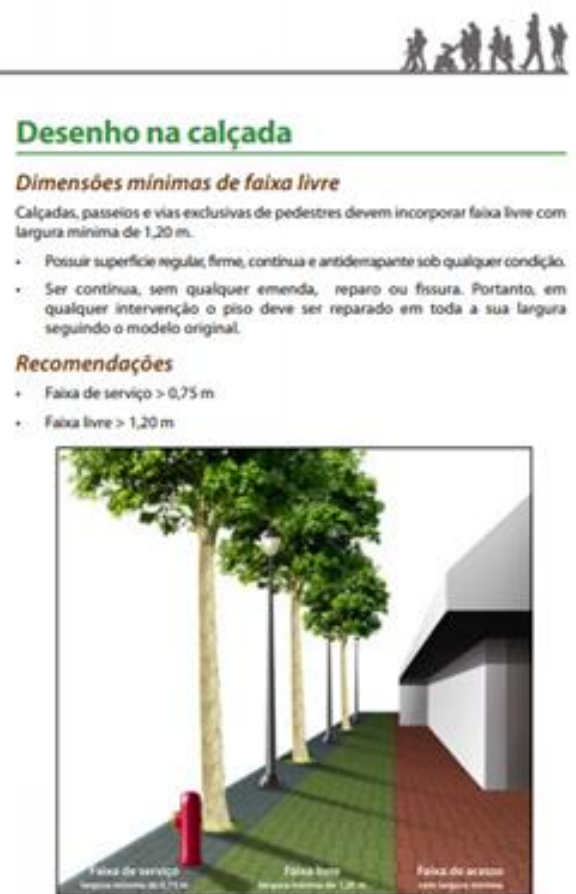

Fonte: http://solucoesparacidades.com.br/wp-content/uploads/2012/08/Guia_construcao_calcadas.pdf

A página representada na Figura 3, apresenta imagens e linguagem textual em forma de títulos, corpo de texto e tópicos. Não há representações humanas. $\mathrm{O}$ ambiente é caracterizado por calçada, arborização, edifício e equipamento, ou seja, apenas elementos de infraestrutura urbana. A imagem é composta pelo predomínio de linhas retas e com imagens coloridas. Os volumes representados são plantas, árvore e gramado, edifícios e equipamentos como: hidrante e porte. Entende-se o contexto pela representação de acessibilidade arquitetônica, ou seja, que elimine obstáculos físicos, sendo a maior representação uma área de circulação.

A seguir, a Cartilha no39, "Cartilha de Acessibilidade das Calçadas de Maceió: Superintendência Municipal de Controle do Convívio Urbano", foi publicada em Maceió- AL (Figuras 4 e 5).

Figura 4: Cartilha no.39. 

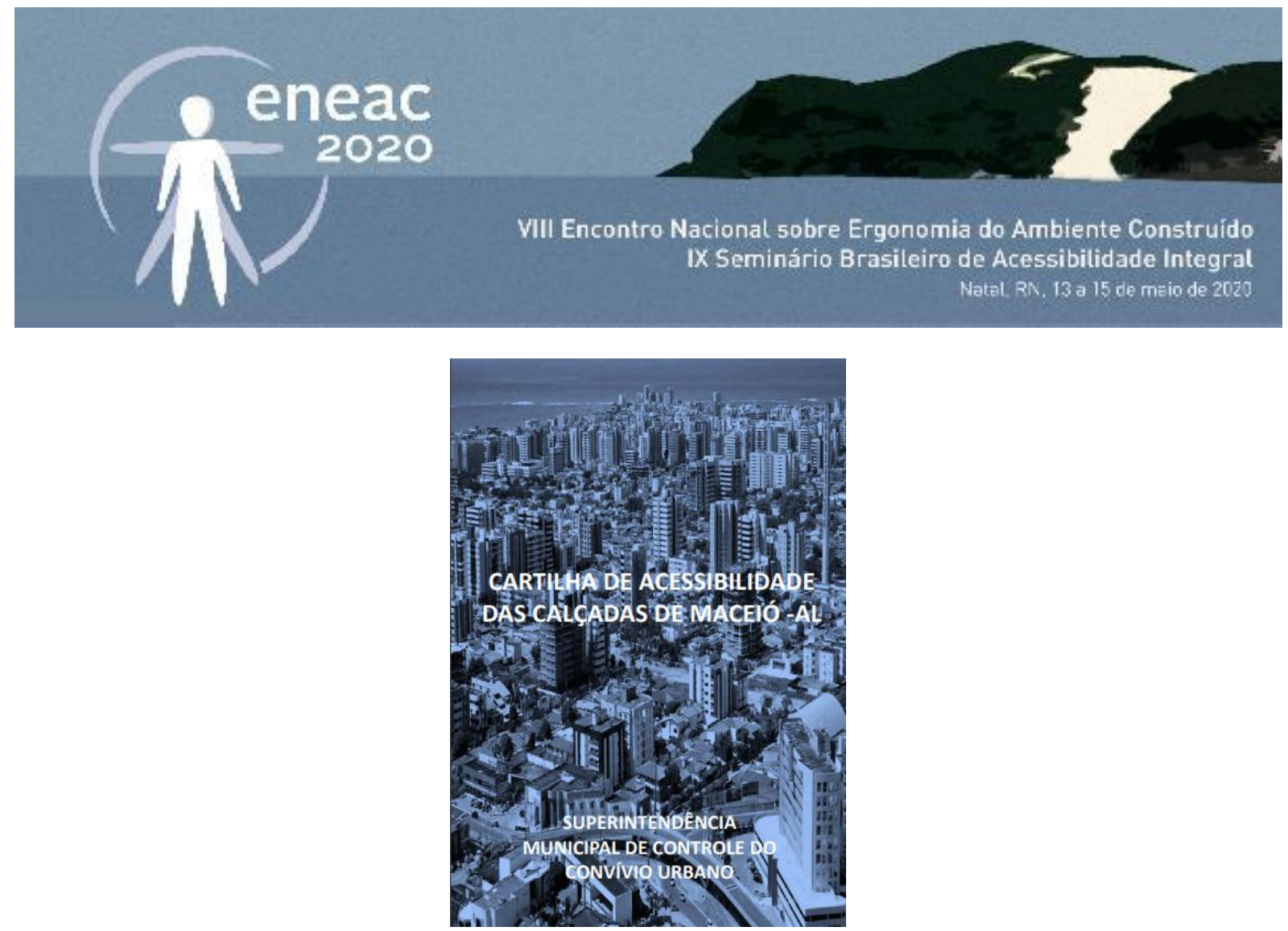

Fonte: http://s3.id5.com.br/crea/uploads/2016/10/CARTILHACALADASSMCCU.pdf

A capa (Figura 4) contém imagens e linguagem escrita em forma de título e subtítulo. A imagem retratada é bem característica a um ambiente urbano, com volumes de: edifícios, ruas, calçadas, elevados, veículos e arborização. A imagem contém linhas retas e curvas com domínio de tons de azul, preto e branco. A capa lembra características de acessibilidade arquitetônica em áreas de circulação. Figuras humanas não são representadas no plano principal.

Figura 5: Cartilha no. 39, p. 2

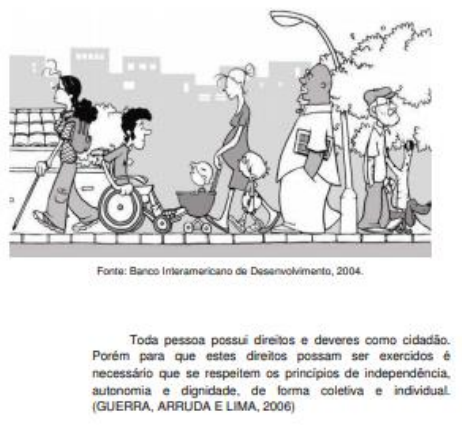




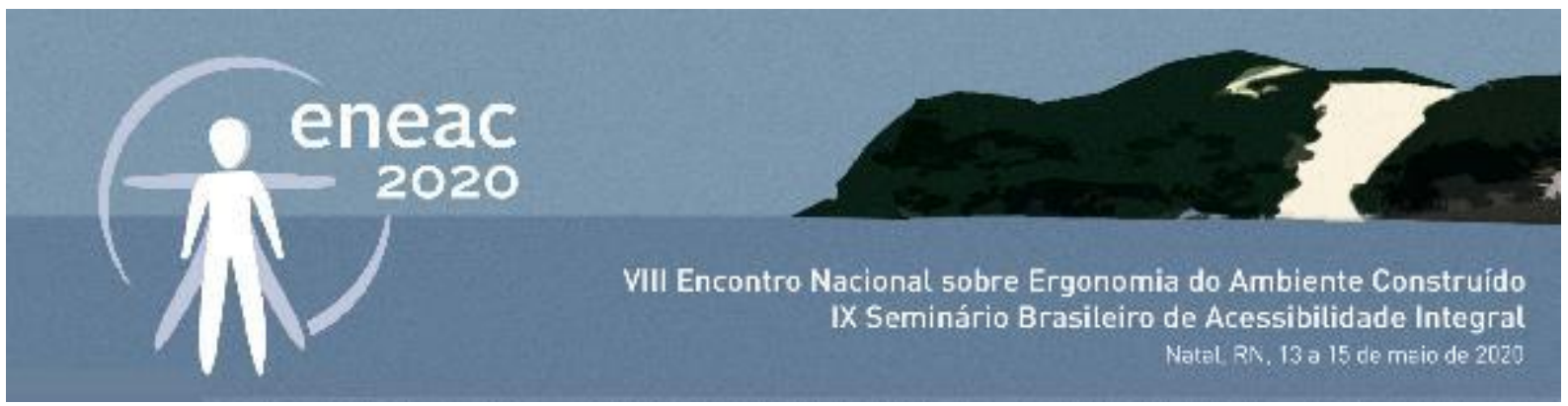

A página reproduzida na Figura 5 apresenta linguagem não verbal que expressa acessibilidade do tipo arquitetônica e atitudinal. Apresenta linguagem escrita em forma de textos e título com subtítulo.

Existe a representação de diversas pessoas, sozinhas ou com suas famílias. Esse volume representado por pessoas tem características diferentes como: deficiente visual, mulher com óculos escuros e bengala; deficiente físico, homem com cadeira de rodas; família, bebê no carrinho, mulher gestante e lactante e criança; e por último pessoas com dificuldade de locomoção, homem com sobrepeso e idoso com seu animal de estimação. A imagem é composta por linhas retas e curvas e domínio de tons preto e branco. $\mathrm{O}$ ambiente urbano é bem característico na imagem, contendo volumes como: animais, árvores, casas, edifícios, rua, calçada, poste e os equipamentos como a bengala, cadeira de rodas e o carrinho de bebê. Entende-se como ponto importante a área de circulação, ou seja, a calçada.

A Cartilha no 40, "Calçada Legal: Como vai sua calçada?", primeira edição de 2017, foi publicada em Manaus- AM (Figuras 6 e 7).

Figura 6: Cartilha no. 40.

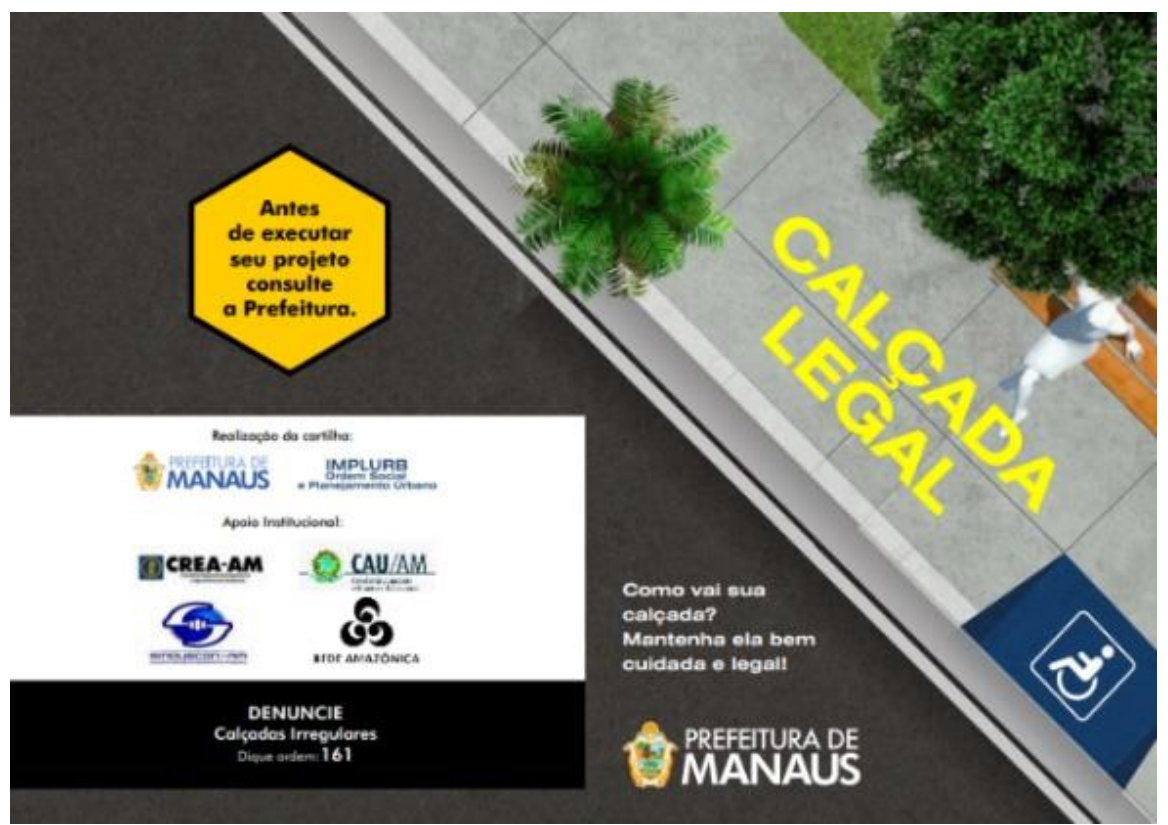

Fonte: https://www.crea-am.org.br/dwl/pag170203_1486151749.pdf

A capa (Figura 6) apresenta linguagem escrita com títulos, subtítulos e siglas de algumas instituições. Existe uma representação humana, que aparece de forma isolada sem qualidades expressionais. Um ambiente urbano com rua e volumes de calçada, sarjeta, arborização, banco e rampa. Apresenta linguagem não verbal referente à acessibilidade arquitetônica em área de circulação. 


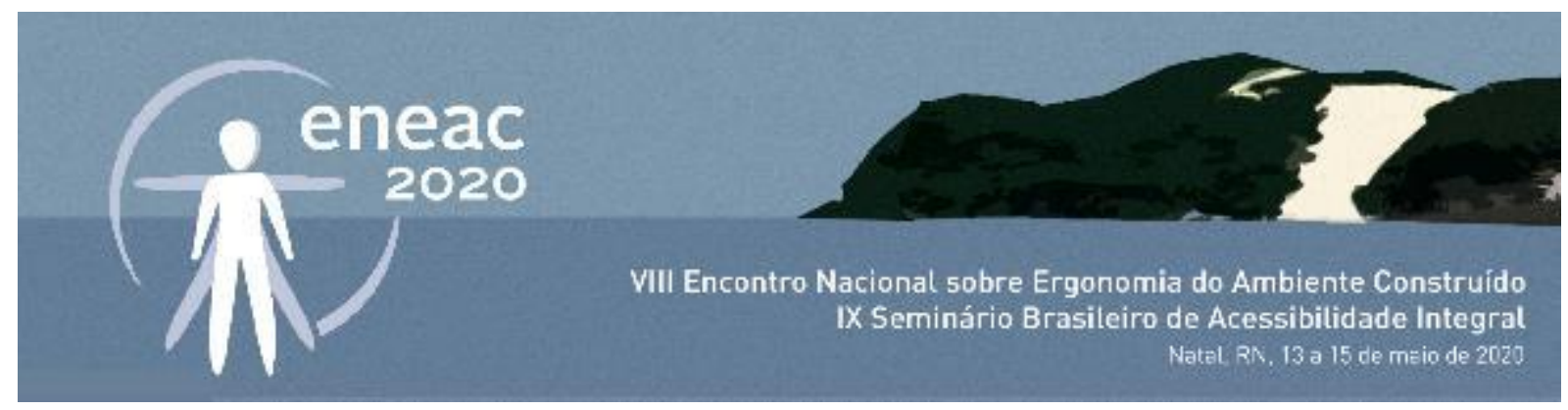

Figura 7: Cartilha no.40, p. 2

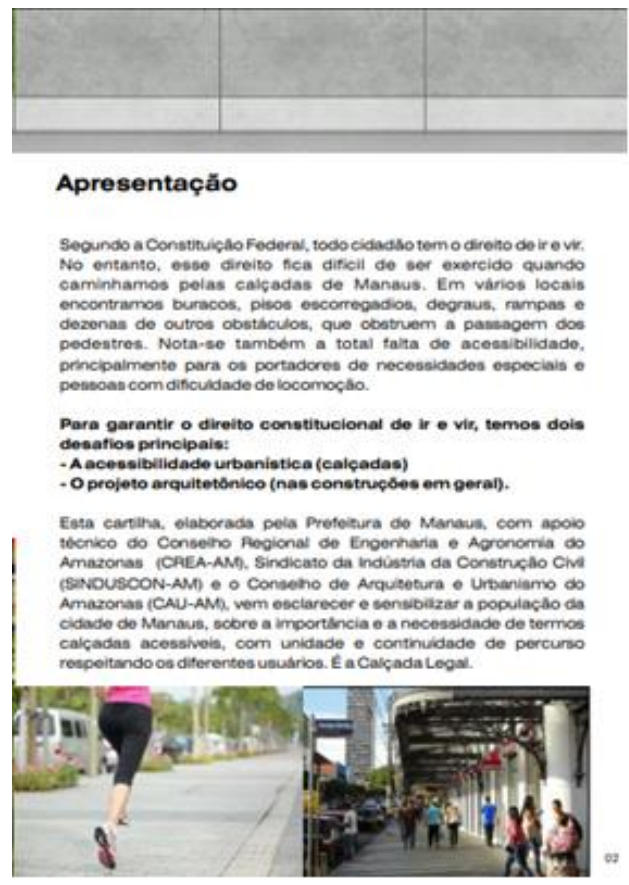

Fonte: https://www.crea-am.org.br/dwl/pag170203_1486151749.pdf

A Figura 7 apresenta a página 2 da cartilha e contém linguagem escrita bem vasta, com título, textos e tópicos com referência a linguagem instrumental. Quando à linguagem visual, a página faz referência à acessibilidade arquitetônica e atitudinal em imagens fotográficas, com mistura de cores e de linhas retas e curvas. Em ambiente urbano com volumes como: plantas, arbustos e árvores; equipamentos: postes, coberturas, placas; calçadas, edifícios e veículos, todos relacionados a áreas de circulação. Quanto à representação de figuras humanas, elas aparecem de diferentes formas, convivendo em sociedade e não há nenhuma representação com características fortes de deficiência ou dificuldade.

\section{DESCRIÇÃO ICONOGRÁFICA DAS CARTILHAS}

Considerando a produção destas cartilhas no Brasil (com o recorte da acessibilidade), a região que teve maior produção foi a região Sudeste, com $36,37 \%$, sendo São Paulo o estado que mais produziu, com 14,54\%, com produção a partir de 2005. A região Centro Oeste vem em segundo lugar, com $30,9 \%$ das cartilhas, impulsionada por Brasília, com $20 \%$ da produção, vale lembrar que, sendo a capital do país, muitas produções e estudos vem de outros locais e são publicados no Distrito Federal. Importante salientar ainda, que das cartilhas selecionadas, a primeira a ser produzida foi no ano de 1997. Infelizmente a região Norte, teve a menor produção do país com muitos estados com produção zero. Se considerarmos as analisadas nesta pesquisa duas delas são do Nordeste (AL e BA) e uma do Norte (AM). 


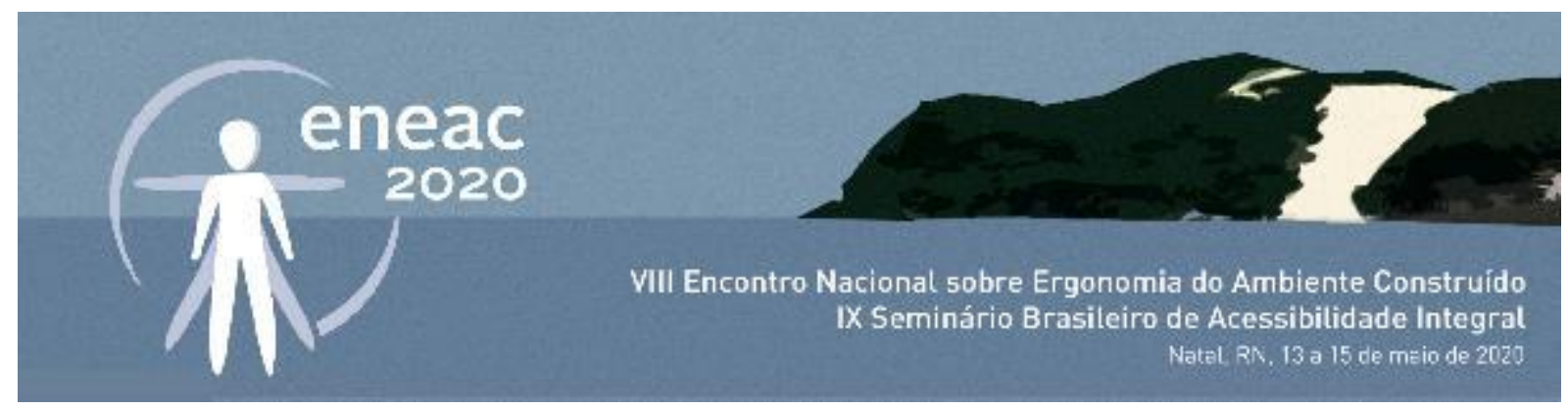

Na pesquisa notou-se também que a internet é a principal difusora das cartilhas, com $100 \%$ das publicações, portanto, essa é a forma mais abrangente de comunicação atual. Todas as cartilhas contêm linguagem escrita e imagens vetoriais ou fotografias.

De maneira geral, pode-se dizer que as cartilhas apresentam falhas na abordagem do conteúdo da acessibilidade, principalmente por não considerar a multiplicidade de deficiências e diferentes condições dos usuários no espaço arquitetônico e urbano. As cartilhas apresentam informações limitadas no aspecto de acessibilidade arquitetônica, ressaltam pequenas características de forma que, em geral, elas não trazem informações mais detalhadas sobre a construtibilidade e materialidade dos ambientes. Ainda há uma ideia restritiva sobre o perfil dos deficientes, considerando o deficiente físico, e em especial o que utiliza cadeira de rodas, como o único que precisa de adaptações do meio. Neste sentido faz-se necessário difundir as outras formas de deficiência e a necessidade de projetar espaços adaptados à maior quantidade de pessoas com diversas dificuldades de acesso. Algumas cartilhas apresentam-se ausentes de representações de pessoas, isso não reflete o objetivo geral, que é a incluir. Agrava-se quando se nota que pessoas são retratadas isoladas no ambiente urbano, e é exatamente isso que se espera não ocorrer, se espera que haja inclusão, convívio e respeito entre todos.

Nota-se na maioria das cartilhas uma preocupação com a vegetação, ou por estética ou para conforto térmico e acústico, sendo este um ponto muito positivo nos materiais divulgados de forma geral.

\section{CONSIDERAÇÕES FINAIS}

A seleção das cartilhas sobre acessibilidade urbana, em especial sobre calçadas, foi adotada como parâmetro de comparação de informações e conteúdo, entre o mesmo assunto. Porém há de se destacar que a quantidade de outros assuntos tratados pelas cartilhas dentro de ambiente urbano não é tão variada. Nas cartilhas pesquisadas nota-se que não há profundidade na abordagem do assunto e que as informações poderiam ser mais precisas.

Observa-se uma profusão de materiais informativos que poderiam auxiliar os profissionais na implantação de políticas de acessibilidade, mas nota-se que há dificuldade de transposição dos sentidos denotativos e conotativos. Materiais gráficos atuam como guias para compreender e orientar melhor através da linguagem do desenho, com informações de fácil interpretação e mais acessíveis do que linguagem legislativa, mas é preciso verificar a eficácia dessas produções, pois alguns conteúdos iconográficos podem ser difíceis de compreender ou o desenho pode sugerir outra interpretação. A produção iconográfica das cartilhas, sofre influência das normas de acessibilidade, como a NBR 9050. Esta Norma, inclusive determina características que devem constar nos instrumentos de leitura, principalmente no quesito legibilidade e tamanho dos caracteres. A falta de estudos iconográficos apropriados, devidamente representativos e abrangentes, é uma lacuna que pode ser melhor explorada. Neste sentido, pretendemos dar subsídios a esta discussão utilizando a metodologia de análise iconográfica, sistematizando os resultados com um número significativo de exemplares estudados (este estudo apresentou 3, por questões de exemplificação ) e assim mostrando a necessidade de novas discussões e observações sobre o tema. 


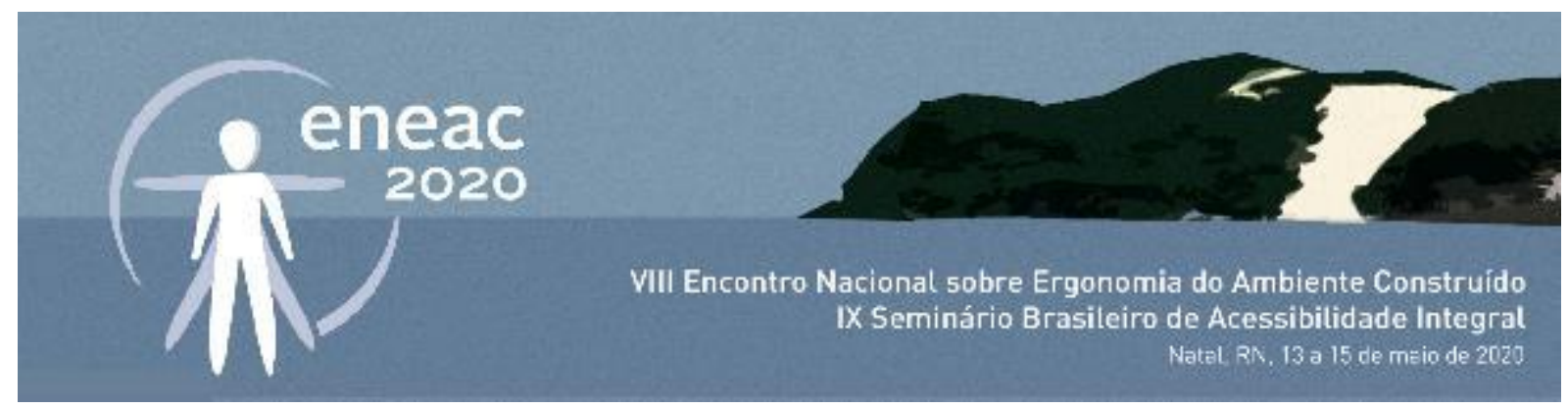

No presente trabalho houve a preocupação com as práticas metodológicas de leitura de imagens, para que a leitura fosse feita da melhor forma possível. A necessidade de novas possibilidades de interpretações, questionamentos, perspectivas de conceitos científicos fazem com que a iconografia seja fundamental na análise de imagens. Através da pesquisa e revisão da literatura disponível foi possível testar a aplicabilidade da metodologia baseada na iconografia para estudo de cartilhas e material gráfico com orientações sobre arquitetura.

Percebe-se a carência de estudos para elaboração de cartilhas e a análise das mesmas evidenciou a necessidade de desenvolver a pesquisa com foco na iconografia, onde a imagem tem a função de descrever e facilitar a compreensão e entendimento do assunto tratado. A imagem tem suas representações e padrões, que podem ser diferentes de acordo com a cultura e o meio, modificando a compreensão e a simbologia. Nesse sentido entende-se como necessário compreender de que forma as cartilhas são apresentadas a partir de seus elementos iconográficos e como eles podem influenciar significantemente na compreensão, na atenção e na correta aplicação dos conceitos.

Verifica-se também a necessidade de preparar mais profissionais que possuam essa percepção iconográfica e que sejam capazes de atuar na interface gráfica que a arquitetura e construção exige. Logo é desejável que mais discussões e cursos possam se suceder para que a descrição iconográfica possa figurar nos trabalhos acadêmicos inspirando as pessoas a procurarem as formas adequadas de traduzir conceitos em imagens.

Quanto à distribuição deste tipo de material, espera-se que seja mais difundido e distribuído na comunidade, desde que corretamente elaborado. A cartilha como instrumento de comunicação é por vezes até didática e pode ser manipulada de diversas formas (em treinamentos de profissionais de áreas correlatas, em diálogos entre a comunidade e os profissionais da área, profissionais de infraestrutura urbana e de mobilidade urbana, na educação infanto-juvenil, por exemplo). O objetivo da cartilha é produzir informações e conhecimento, sensibilizando o leitor para a relevância dos conceitos inseridos, contribuindo para a melhoria da qualidade de vida, porém, muitas delas acabam não conseguindo atender a esse propósito, ora por desviar do assunto com outros propósitos, ora por falta de conhecimento técnico e sensibilidade do autor.

Destaca-se assim, a importância de utilizarmos a análise iconográfica no processo de construção e preparação de materiais de apoio à profissionais das áreas técnicas, população em geral e particularmente a pessoas com necessidades específicas, uma vez que somente através de um estudo cuidadoso, utilizando aspectos das formas, objetos e eventos presentes na imagem, limitando-se aos motivos como linhas, cores e volumes (descrição pré-iconográfica); ao aspecto da ligação das composições da imagem com assuntos e conceitos da percepção das convenções sociais e culturais (descrição iconográfica) e finalmente o aspecto da interpretação dos valores simbólicos da imagem, onde estão entrelaçadas preocupações do contexto na produção, como fatores históricos e sociais (descrição iconológica) é que poderemos atingir um melhor nível de apresentação destes materiais.

Algumas questões ainda podem ser investigadas em trabalhos futuros, por exemplo, como a imagem pode melhorar a compreensão do conceito de acessibilidade e Desenho Universal, que tipo de cuidado é necessário ter nas representações gráficas para não ferir códigos de respeito e civilidade, como as representações podem expressar valores sociais e comunitários. São questões importantes a serem investigadas sob o viés da descrição iconográfica e iconológica, que permitirão uma 


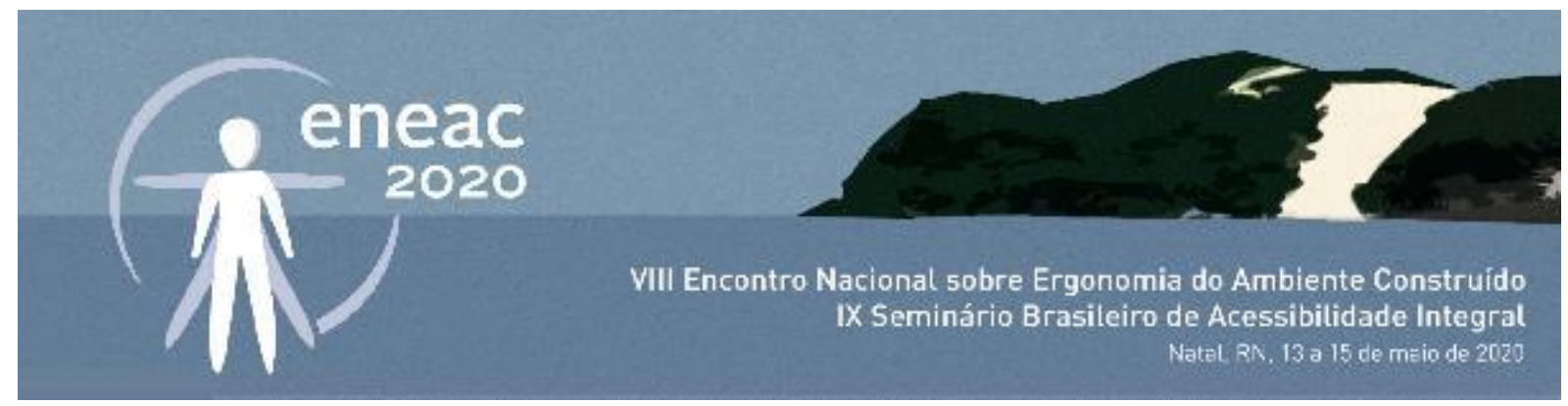

amplitude na interpretação de imagens e mensagens presentes em cartilhas de orientação de acessibilidade.

\section{REFERÊNCIAS}

ABNT. ASSOCIAÇÃO BRASILEIRA DE NORMAS TÉCNICAS. NBR 9050: Acessibilidade a edificações, mobiliário, espaços e equipamentos urbanos. Rio de Janeiro, 2015.Disponível em <http://portal.mj.gov.br/corde/arquivos/ABNT/NBR1532 $0 . p d f>$. Acesso em 28/08/2018.

BURKE, Peter. Testemunha Ocular: história e imagem. Bauru: Edusc, 2004. 270 p. Tradução: Vera Maria Xavier dos Santos. Disponível em: <https://pt.scribd.com/document/376288422/Peter-Burke-Testemunha-ocular-Historia-e-Imagem-OCRpdf>. Acesso em: 02 out. 2018

CREA-BA. Guia Prático para a Construção de Calçadas. 2a ed. Salvador. 2007-2010. Disponível em < http://solucoesparacidades.com.br/wp-content/uploads/2012/08/Guia_construcao_calcadas.pdf>Acesso em 30 de outubro de 2018

Declaração Universal dos Direitos Humanos. Nações Unidas, 217 (III) A, 1948, Paris, art. 1, http://www.un.org/en/universaldeclaration-human-rights/. Acessado em 6 de setembro de 2018.

GOMEZ, Alberto Perez (1982). Architecture as Drawing, Journal of Architectural Education, 36:2, 2-

7, DOI: $10.1080 / 10464883.1982 .10758306$

MACE, Ronald L.; HARDIE, Graeme J. PLACE, Jaine P. Accessible Environments: Toward Universal Design. Raleigh, NC: Center for Universal Design, 1996.

MOLINA, Lucas Giehl. Da Prática a Teoria: O método Iconológico de Erwin Panofsky $(1921,1939,1955)$. 2010. Disponível em: <https://www.academicoo.com/artigo/da-pratica-a-teoria-o-metodo-iconologico-de-erwin-panofsky-1921-1939-1955>. Acesso em: 04 set. 2018

ONU. Assembleia Geral das Nações Unidas. A ONU e as pessoas com deficiência. Disponível em: < https://nacoesunidas.org/acao/pessoascomdeficiencia > Acesso em: 18/06/2018

OLIVEIRA, Terezinha; NUNES, Meire Aparecida Lóde. Análise Iconográfica: Um Caminho Metodológico de Pesquisa em História da Educação. Revista Contrapontos, Itajaí, v. 10, n. 3, p.307-313, set. 2010. Disponível em: <https://siaiap32.univali.br/seer/index.php/rc/article/view/2100/1719>. Acesso em: 07 nov. 2018.

PANOFSKY, Erwin. Significado nas Artes Visuais. 3. ed. São Paulo: Editora Perspectivas, 1991. 217 p. Tradução: Maria Clara F. Kneese eJ. Guinsburg. Disponível em: <https://www.passeidireto.com/arquivo/38312319/erwin-panofsky-significadonas-artes-visuais-pdf>. Acesso em: 16 out. 2018

PREFEITURA DE MACEIÓ. Cartilha de acessibilidade das calçadas de Maceió superintendência municipal de controle do convívio urbano -AL. Maceió. Disponível em < http://s3.id5.com.br/crea/uploads/2016/10/CARTILHACALADASSMCCU.pdf> Acesso em 03 de março de 2019.

PREFEITURA DE MANAUS. Calçada Legal. Como vai sua calçada? Manaus. 2017. Disponível em < https://www.creaam.org.br/dwl/pag170203_1486151749.pdf> Acesso em 03 de março de 2019.

RODRIGUES, Ricardo Crisafulli. 67 Ci. Inf., Brasília, v. 36, n. 3, p. 67-76, set./dez. 2007. Análise e tematização da imagem fotográfica. Ibict Ciência da Informação, Brasília, v. 36, n. 3, p.67-76, jul. 2007. Semestral. Disponível em:

<http://www.scielo.br/scielo.php?pid=S0100-19652007000300008\&script=sci_abstract\&tlng=pt>. Acesso em: 07 abr. 2019.

SASSAKI, Romeu Kasumi. Inclusão: Construindo Um a Sociedade Para Todos. 1ạ edição. Rio de Janeiro: WVA, 1997 Disponível em < http://centraldosmelhoreslivros.blogspot.com/2011/05/livros-loureiro-romeu-k-sassaki.html > Acesso em 05/05/2019

TOGNON, Marcos. O desenho e a história da técnica na arquitetura do Brasil colonial. Varia Historia, [s.I.], v. 27, n. 46, p.547-556, dez. 2011. FapUNIFESP (SciELO). http://dx.doi.org/10.1590/s0104-87752011000200008. Disponível em: <http://www.scielo.br/scielo.php?script=sci_arttext\&pid=S0104-87752011000200008\&lng=pt\&tlng=pt $>$. Acesso em: 28 abril 2019. 